\title{
Demography of the Santals in West Bengal and Jharkhand: A Comparative Study
}

\author{
Sudip Datta Banik \\ Department of Anthropology, Vidyasagar University, Midnapore (W) 721 102, \\ West Bengal. India \\ Telephone: 9433186993 (Mobile).E-mail: sdbanik @ hotmail.com
}

KEYWORDS Santals; tribals; demography; sex-ratio

\begin{abstract}
A systematic micro demographic study with special emphasis on sex-ratio (Female - Male ratio or FMR) patterns among the Santals in nineteen villages of the bordering districts of the states of West Bengal and Jharkhand comprises 2257 male and 2135 female individuals. Sex-ratio patterns among the Santals exhibit low FMR (946), compared to the all-India FMR ST $_{1} 972$ (Census of India, 1991). However, the average FMR (946) of the Santals in this area, has been found to be little higher than the average FMR ( $_{4}$ il in Census of India, 1991) of these two neighbouring states. Santals of Jharkhand also show higher FMR (964) in comparison with those of West Bengal (935). FMR of all age goups among the Santals in Jharkhand exceed the FMR of the Santals in West Bengal, except that in the age-group of 10-14 years. In both the states, a decline of $\mathrm{FMR}_{59}$ from $\mathrm{FMR}_{04}$ indicates a trend of excess girl-child mortality among the Santals. However, a decadal increment of FMR among the Santals in this region is observed from the higher value of FMR than $_{\text {FMR }}{ }_{10}$. Substantial female labour participation (FLP) is reflected from FMR $15-44$ and FMR ${ }_{15-64}$ among the Santals, especially those of Jharkhand. Further, percentage of persons $(0-4$ years and $0-14$ years), work-participation rate and age-dependency ratio are found to be higher among the Santals of Jharkhand. In contrast, child-woman ratio and percentage of old-age population among the Santals of West Bengal are recorded as higher than the Santals of Jharkhand.
\end{abstract}

\section{INTRODUCTION}

The tribes of India comprise approximately $8 \%$ of the total population of the country, having probably the largest number of tribal communities in the world (Topal and Samal, 2001). 5.62\% and $30.75 \%$ of total populations in West Bengal and Jharkhand respectively, belong to the Scheduled Tribe (ST) section (Mondal, 2002). Various tribal populations are among the most underprivileged and undernourished people in India (Bose et al., 2006). Demographic data of different tribal populations are urgently required in order to estimate the biological, social and economic status of the tribals of India and thereby to take appropriate measures towards the development of different communities. Diverse ecozones and multiple ethnic components of the Indian tribal populations with their wide-ranging socioeconomic and cultural patterns, their biological variations and discrete dietary habits altogether constitute the multidimensional complex of needs for investigation and data from different communities.

Sex-Ratio indicates the relative frequency of one sex over the other. This particular term however, has been used to mean various measurements. Sometimes it means, the proportions of males in a population, sometimes males percent or per thousand females, sometimes females per cent or per thousand males or FMR (Census of India). In this present study, sex ratio means FMR. Sex ratios are calculated at different stages of life. In all populations there is a distortion of sex-ratio from the expected 1:1 ratio. This distortion shows racial and ethnic variations. Rural-urban and socio-economic differences in sex-ratio are also reported (Burnstein, 1958).

Sex-ratio is one of the most significant demographic indicators that help in estimating the nature of population structure, apprehends the trends of gender-bias at any age or agegroup(s). Sex-ratio also indicate the role and status of women in a society, their involvement in economic pursuits and also help in measuring gross fertility, and relative mortality rates of the two sexes at different ages. Sex-ratio patterns in a population also measures dependency ratio and work-participation rate and also directly and indirectly reflect other social and economic correlates of the community.

Analyses and evaluations of FMR in the domains of academic and population policy discourses have become one of the major concerns for the experts and demographers of 
Indian population. The higher masculine sexratios are the matters of concern in census operation in India over decades. In this country, FMR (all populations) indicates a gradual decline (from 972 to 933) since 1901 to 2001 , excepting marginal rises in 1951 and 2001. The decline of FMR (from 987 to 972) is also a fact in case of the Scheduled Tribe (ST) populations in India since 1961 to 1991, excepting a negligible reversal in 1971-1981. The FMR ${ }_{\mathrm{ST}}$ of undivided Bihar state conforms to the all India trend of decline whereas in West Bengal, a remarkable rise of FMR is noted since 1961 to 2001 (Census of India 2001). The FMR of western countries show higher values through decades, when compared with Asia, China and Indian subcontinent (comprising India, Pakistan and Bangladesh) (Agnihotri, 2000; Census of India, 2001).

\section{Previous Studies}

Micro level demographic studies including sex ratio patterns in different Indian populations are numerous (Harriss, 1989). In India, high infant mortality sometimes distorts the high sex ratio at birth (Dasgupta et al.,1955). Dutta (1961) suggested that the higher female sex ratio of ancient India was maintained in southern and eastern India compared to North-West where mixture with Aryans who had shortage of women might have reduced the proportion of female in the population.

Most of the previous studies on sex-ratio patterns of Indian populations are based on the analyses of the data of 1961 census of India (Visaria, 1971 ; Miller, 1981 ) and 1981 census of India (Visaria and Visaria, 1981). Agnihotri (2000) critically examined the facts and figures of disaggregation of sex-ratio (FMR) patterns and causes for low and declining proportions of females in India's population. This study was also focussed on the 1961 as well as 1981 district level population census data of India. The problem of low FMR in Indian populations, its causes and consequences were discussed in a number of previous works which may be classified in four different dimensions: a) high masculine sex ratios at birth; b) sex-selective migration; c)sex-selective enumeration errors (Chen, 1982; Srinivasan, 1994) and gender bias (Agnihotri, 2000; Caldwell and Caldwell, 1990; Harriss, 1989; Hill and Upchurch, 1995; Visaria 1988; Waldron 1983). The importance of female labour participation (FLP) had been highlighted by Bardhan (1974). Miller (1981) emphasized upon the effects of FLP on sex ratios.

Low FMR and its steady decline over decades with regional and ethnic variation is a significant phenomenon under constant investigation. High masculine sex-ratio apparently reflects the discriminatory outlook against female members of a society, giving rise to excess female over male mortality. Discrimination against women, operating through their unequal access to life-sustaining inputs like food, nutrition and health-care (Miller 1981) consequently lead to sex-differentials in mortality and low FMR. This is particularly so for female children in the juvenile age-group (Agnihotri, 2000).

Essentially, the studies in sex-ratio in different populations can best be understood by microdemographical investigation. The spatial-temporal distribution of different Austric-speaking tribal populations in the ecozones of Chotanagpur plateau region in Eastern India offer significant scope in the study of tribal populations with different demographic, biological, socioeconomic and cultural attributes. The sociodemographic study of the tribal society and population and their structure and change over time, reflects the patterns of spatial concentration and density of these populations in this region. The empirical facts and figures, provide some valuable information on this particular issue, at least from this part of the Eastern India. The present report is a preliminary attempt in this direction.

\section{MATERIAL AND METHOD}

This particular study was undertaken in 19 villages, exclusively inhabited by the Santals. Twelve villages from three districts viz. Paschim Medinipur, Bankura and Purulia of the state of West Bengal and Seven Villages from two districts viz. Purbi Singhbhum and Dumka of Jharkhand state have been selected for this investigation. The study population comprised 4392 Santals individuals (2257 males and 2135 females).

Data collected through specific family-level demographic methods, have been classified in precise age-sex structure. Moreover, a few age groups like 0-9, 0-14, 10-19, 15-44 and 15-64 have been clustered to enquire into some essential issues related to the different demographic situations of the community. The different 
demographic ratios viz. variations in sex-ratios (FMR) by age, child-woman ratio, age and economic dependency ratios spell about varied dimensions of demographic and socio-economic life and ways of the Santals in this region.

\section{RESULTSAND DISCUSSION}

\section{Sex-ratio Patterns}

Conspicuous disaggregations of FMR in agesex composition of the population, and variations at the state as well as regional levels have been reported in this study. Data of all the districts of the respective state have been pooled as the representative figure for that particular state.

According to the Census of India 1991, allIndia $\mathrm{FMR}_{\mathrm{ST}}$ Was recorded as 972 in comparison with 968 of this eastern region (average value of West Bengal and Jharkhand). Our result exhibits low FMR (946), compared to the FMR $\mathrm{ST}_{\mathrm{S}}$ of both the all-India and of this eastern part. The Santals in West Bengal and Jharkhand separately also show lower FMR than the FMRST (Census of India 1991) of these two states. Therefore, conforming the trend of decline of $\mathrm{FMR}_{\mathrm{ST}}$ over decades at national level a further decadal trend of decline of $\mathrm{FMR}_{\mathrm{ST}}$ (968 to 946) may be apprehended from the present data (collected in 2002) which is compared with the data of Census of India 1991. However, this proposition needs further verification since the sample size of the present study is too small to compare with the huge tribal population of this part of India and only one tribal community has been considered for the present analysis (Table 1).

In the study, the regional distinctions of
FMRST when observed, the district and statelevel variations and comparison between different age-groups are found quite inconsistent whereas each area shows some specific variations in different age-groups.

In a comparative estimate of FMR between the two states, FMR (all ages) of the Santals in Jharkhand (964) is found to exceed the FMR (935) of the same tribal community in the state of West Bengal (table II). FMR04 among the Santals (995) is observed to be similar in the two states (Table 2). However, a decline of FMR59 (952 in West Bengal and 972 in Jharkhand) in this community (962) from the previous age-group, indicate excess girl-child mortality. Further decline of $\mathrm{FMR}_{10-14}$ (928) in both the states confirm the trend of sex-selective removal of women and also indicate a psyche of preference for male-child in Santal society. However, it may be mentioned that from demographic point of view, the decline of $\mathrm{FMR}_{59}$ from $\mathrm{FMR}_{04}$ is a frequent phenomenon in all-Indian populations. (Agnihotri, 2000).

A decadal variation of FMR is recorded when an increment of $\mathrm{FMR}_{59}$ from $\mathrm{FMR}_{10-14}$ and $\mathrm{FMR}_{10-19}$ is observed. This rise of FMR may be considered as a reflection of decadal growth of economy, literacy and awareness among the Santals in this region and their change of preference for male-child only. Sex-ratio (FMR) in adolescent and juvenile age-group $\left(\mathrm{FMR}_{10-19}\right.$ $=803$ ) is remarkably low. FMR $10-19$ in Jharkhand (678) is alarming, compared to a low but moderate FMR $_{10-19}$ (927) among the Santals of West Bengal (Table 2).

The FMR values in the ages of 60 years and above are found to be not consistent enough owing to small sample size and the magnitude of

Table 1: Comparative statement between the data of the Census of India 1991 and present data of demographic indicators among the Santals.

\begin{tabular}{|c|c|c|c|c|c|c|}
\hline \multirow[t]{2}{*}{ Demographic indicators } & \multicolumn{3}{|c|}{ Census of India 1991} & \multicolumn{3}{|c|}{ Present Data } \\
\hline & $\begin{array}{l}\text { Bihar } \\
\text { (Jharkhand) }\end{array}$ & $W . B$. & Average & $\begin{array}{l}\text { Bihar } \\
\text { (Jharkhand) }\end{array}$ & $W \cdot B$. & Average \\
\hline FMR & 971 & 964 & 941 & 964 & 935 & 946 \\
\hline $\begin{array}{l}\% \text { of persons }(0-6) \text { years } \\
\text { (Male }+ \text { Female })\end{array}$ & 20.12 & 19.46 & 19.79 & 12.29 & 11.25 & 11.67 \\
\hline $\begin{array}{l}\text { Work-Participation Ratio } \\
\text { (Male + Female) }\end{array}$ & 45.67 & 47.66 & 46.67 & 61.79 & 58.91 & 60.06 \\
\hline Literacy Rate & $\begin{array}{l}\text { Bihar } \\
\text { (Jharkhand) } \\
\text { and W.B. } \\
\text { Male (\%) } \\
39.24\end{array}$ & $\begin{array}{l}\text { Bihar } \\
\text { (Jharkh } \\
\text { and W.I } \\
\text { Female } \\
14.87\end{array}$ & & $\begin{array}{l}\text { Bihar } \\
\text { (Jharkhand) } \\
\text { and W.B. } \\
\text { Male (\%) } \\
37.24\end{array}$ & $\begin{array}{l}\text { Bihar } \\
\text { (Jhark } \\
\text { and W } \\
\text { Femal } \\
16.58\end{array}$ & $\begin{array}{l}\text { and) } \\
\text { (\%) }\end{array}$ \\
\hline
\end{tabular}

(Mondal et al., 2002; Census of India, 2001; Bose, 1996). W.B. means West Bengal 
Table 2: Comparative statement of demographic indicators among the Santals : regional variations (present data)

\begin{tabular}{|c|c|c|c|c|c|}
\hline S.No. & $F M R$ & \multicolumn{2}{|c|}{ Total of present data } & Jharkhand & West Bengal \\
\hline 1 & FMR (ALL AGES) & 946 & & 964 & 935 \\
\hline 2 & FMR 04 & 995 & & 995 & 994 \\
\hline 3 & FMR 59 & 962 & & 972 & 952 \\
\hline 4 & FMR 09 & 979 & & 985 & 972 \\
\hline 5 & FMR 0-14 & 953 & & 951 & 955 \\
\hline 6 & FMR 10-19 & 803 & & 678 & 927 \\
\hline 7 & FMR 15-44 & 972 & & 993 & 951 \\
\hline 8 & FMR 15-64 & 980 & & 994 & 966 \\
\hline 9 & FMR $64+$ & 1046 & & 1375 & 717 \\
\hline \multicolumn{2}{|c|}{ Demographic indicators } & MEAN & $V \pm S D$ & $M E A N \pm S D$ & $M E A N \pm S D$ \\
\hline 10 & Child-Woman Ratio & 0.51 & \pm 0.06 & $0.48 \pm 0.00$ & $0.53 \pm 0.08$ \\
\hline 11 & Age Dependency Ratio & 0.61 & \pm 0.09 & $0.67 \pm 0.08$ & $0.57 \pm 0.08$ \\
\hline 12 & Percentage of persons (0-4) & 11.67 & \pm 1.98 & $12.29 \pm 0.15$ & $11.25 \pm 2.68$ \\
\hline 13 & Percentage of persons $(0-14)$ & 31.72 & \pm 9.70 & $36.88 \pm 0.57$ & $28.28 \pm 12.0$ \\
\hline 14 & Percentage of old-age population & 1.95 & \pm 0.99 & $1.02 \pm 0.12$ & $2.57 \pm 0.71$ \\
\hline 15 & Work Participation Rate & 60.06 & \pm 3.05 & $61.79 \pm 0.03$ & $58.91 \pm 3.69$ \\
\hline
\end{tabular}

$\mathrm{SD}=$ Standard Deviation

fluctuation in sex-ratios increased further in older age-groups (70+). This phenomenon leads us to presume a shorter life expectancy of the tribals and non-availability of life-sustaining inputs like modern health-care facilities, which have been noticed during the ethnographic survey in this region.

\section{Growth and Fertility of Populations}

Changes in population size and composition may occur through a change in one or more of the three demographic processes: fertility, mortality and migration. Population growth, fertility and correlation with economic dimension of life of the Santals and the Lodhas are measured in this present context through demographic parameters.

As a measure of fertility, child-woman ratio acts as a significant index, which is determined by the ratio of children under age of five to per thousand women of child-bearing age usually as 15 - 44. Davis (1951) computed the average child-woman ratio from the data of Census of India 1911, 1921 and 1931, in which he found the ratio for the tribals in India as 808 (children of 04 years of age per 1000 women of $15-39$ years of age). In 1961 Census of India, data from Madras (now Chennai of the state of Tamil Nadu) showed the ratio for S.T. population as 659 (Nag 1973). The present study exhibits quite poor value (470) for the Santals. This low value may be due to the adoption of birth control measures among the Santals in recent past. FMR ${ }_{(15-44)}$ and the other measures like percentage of persons ( 0 - 4 years) and ( 0 - 14 years) are often observed as indicators or factors either associated with or influencing fertility and growth of population. The Santals have FMR $_{15-44}$ (972) which indicates moderate to high proportion of females in reproductive age. But this may not be correlated with either percentage of persons $(0-4$ years) $(11.67 \%)$ or low child-woman ratio $(0.51 \pm 0.06)$. Low fertility in spite of high FMR ${ }_{15-44}$ may be due birth control. With regard to the regional variation, the Santals of Jharkhand have higher (993) than those (951) of West Bengal. In case of child- woman ratio, scenario at West Bengal is however, is slightly better $(0.53 \pm 0.08)$ than the Santals in Jharkhand $(0.48 \pm 0.0)$. In contrast, the Santals show little higher $(12.29 \% \pm 0.15)$ percentage of persons $(0$ - 4 years) than the situation $(11.25 \% \pm 2.68)$ of the community in West Bengal (Table 2).

Proportion of children and adolescents, as measured by percentage of persons ( 0 - 14 years) is substantial, having around 32 percent of the total population. In this context, higher percentage $(36.88 \% \pm 0.57)$ of population of 0 14 years of age-group has been recorded among the Santals of Jharkhand than the low value (28.28 \pm 12.0 ) in West Bengal. Very low percentage of old-age population among the Santals in both the states $(2.57 \%$ in West Bengal and $1.95 \%$ in Jharkhand) apprehends shorter life-span of the people which may be due to undernutrition or non-availability of proper medical and other lifesupporting facilities for health and hygiene. 


\section{Economic Dimension of Life of the Santals}

Female labour participation (FLP) is an important indicator of economic correlate in a population. FMR $\mathrm{FM}_{04}-$ FLP and $\mathrm{FMR}_{59}-$ FLP relationships emerge as good indicators of the survival adversities for female children, which are presented as moderate profile for the females among the Santals. Participation of women in economic activities are also reflected from $\mathrm{FMR}_{15}$ ${ }_{64}$ which is moderate for the Santals (980). Male section of Santal community is engaged in agricultural activities where less FLP is required compared to males. This helps us to understand the active role played by the Santal women in the society and economic pursuits of which are either gathering of forest produces or earning as daily labourers. However, more or less satisfactory FLPs are qualitatively estimated from the FMR values in both the states which evaluate the worth and importance of both the children as well as adult females in the community, determining their valuable status and level of prosperity in the societal context and also in the households.

Work participation rate and age dependency ratios are the other measures for understanding the economic life of a population. Both the indices show positive results in the study population with regard to their economic dimensions of life. Age dependency ratio, as measured by a ratio of the sum of number of persons in the age groups $0-14$ and above 64 to the population of age - group 15 - 64 exhibits moderate value (0.61 \pm 0.09 ) for the population. Hence a large section of population among the Santals is dependent upon the working population of the community.

Work participation rate always keeps the S.T. population $(49.3 \%)$ in higher rank than the general population $(37.5 \%)$, as evident from Census of India (2001). Average work participation rate of the tribals in the two states was found to be $46.67 \%$ (Census of India 1991). Results of the present study exhibits better work participation rate between both the Santals $(60.06 \%)$ than the data of Census of India (1991 and 2001) (Table 2).

\section{Literacy Rates}

This index shows that 29.6 percent of males and 18.2 percent of females of S.T. populations in India are literate in comparison to 52.3 percent of males and 39.3 percent of female literates of general populations (Census of India 1991). Regional census data also show that $39.24 \%$ of males and $14.87 \%$ of females of the S.T. populations in the States of West Bengal and Jharkhand jointly are literate. In the present study, lower proportion of Santal males (37.24\%) are literate in comparison to the eastern regional data in this aspect. which is however higher than the national level value of the Census of India. For females, literacy rate is, $16.58 \%$ for the Santals, which more or less conforms to the national as well as regional level values of the Census of India (Table 1).

\section{DISCUSSION}

Census of India data on growth and variation of ST population in India show gradual decline of percentage of ST populations in West Bengal and undivided Bihar and Jharkhand since 19611991 (Mondal, 2002). This trend is however, a kind of reversal when data of ST population are considered in the perspective of all-India level (Bose1996). The trend of gradual decline of both the percentage of ST population as well as the $\mathrm{FMR}_{\mathrm{ST}}$ values in eastern India found from the data of all sources, including the present study may lead us to apprehend a further shortfall in percentage of tribal women population in forthcoming years. This might be a crucial issue at the moment for the demographers and population policy makers.

The Santals as the most dominant agriculturist tribe in this eastern part of India are observed to have better life-conditions in comparison to other tribal groups in this region. However, with respect to the national level demographic standards of Scheduled Tribe populations (as per data of Census of India), the Santals under study exhibit lower level of rankings in most of the parameters like sex-ratio, growth and fertility and literacy status. Fertility and growth of the Santals are not so remarkable and comparatively low FMR in different ages indicate survival adversities for female children and low status of women in tribal societies. Demographic index also apprehends shorter life-span of the tribals in Jhargram. These data and results need further verifications. However, the results of this preliminary enquiry may be helpful for the demographers and policy makers to develop population health measures for the welfare of the tribals in this region. 


\section{REFERENCES}

Agnihotri, S.B. 2000. Sex-Ratio Patterns in Eastern Indian Population - A Fresh Exploration. New Delhi: Sage Pub.

Bose, A.1996. India's Basic Demographic Statistics. Delhi: B.R.Pub. Corp.

Bose K, S. Banerjee, S. Bisai, A.Mukhopadhyay, M. Bhadra. 2006. "Anthropometric profile and chronic energy deficiency among adult Santal tribals of Jhargram, West Bengal, India: Comparison with other tribal populations of Eastern India". Ecol. Food Nutr; 45: 1-11.

Bardhan, P.K. 1974. "On Life and Death Questions". Economic and Political Weekly, Special Issue No.9: 1293-1304.

Burnstein, M.E. 1958. "Studies in Human Sex-Ratio. A Genetic Explanation of the War-Time Increase in the Secondary Sex-Ratio". Am. J. Hum. Genet., 10: 68-70.

Caldwell, J.C. and P. Caldwell. 1990. "Gender Implications for Survival in South Asia". Health Transition Working Paper No. 7. Canberra : NCEPH, Australian National University.

Census of India 1991. cited in Mondal, H (2002).

Census of India 2001. Web Edition. Provisional Population Total.

Chen, L.C. 1982. "Where have the Women gone?" Economic and Political Weekly, 6: 364-72.

Das Gupta, D.A., R.K. Som, M, Majumdar and S.N. Mitra 1955. "Couple Fertility". National Sample Survey No.7. Govt. of India.

Davis, Kingsley 1951. The Population of India and Pakistan. P.80. Princeton. New Jersey: .Priceton University Press.
Dutta, J.M. 1961. "Was There a Shortage of Women in Ancient India?" Man in India. 41: 184-193.

Harriss, B. 1989. "Differential Child Mortality and Health Care." South Asia J. Soc. Studies, 44: 2123 .

Hill, J. and P. Upchurch. 1995. "Gender Differences in Child Health: Evidence from the Demographic and Health Surveys." Population and Development Review, 21(1): 127-151.

Miller, B.D. 1981. The Endangered Sex. Ithaca, N.Y.: Cornell University Press.

Mondal, H., S. Mukherjee and A.Datta 2002. India: An Illustrated Atlas of Tribal World. Kolkata: Anthropological Survey of India Pub.

Nag, M. 1973. "Tribal-Non Tribal Fertility Differentials in India." Demography Today, 2(1): 104-120.

Srinivasan, V. 1994. "Sex Ratios- What They Hide and What They Reveal." Economic and Political Weekly, 30(51): 3233-3234.

Topal, Yeshpal S. and P.K.Samal. 2001. "Causes for variation in social and economic conditions

among tribes of Indian Central Himalaya. A comparative study." Man in India, 81 (I and II.): 87-88.

Visaria, P. 1971. "The Sex-Ratio of the Population of India". Monograph No. 10. Census of India 1961. New Delhi. Office of the Registrar General, India. Visaria, P 1988. "Level, Trends and Determinants if Infant Mortality in India." (pp. 67-126.) in A. Jain and P. Visaria, P (eds.). (cited in Agnihotri, 2000).

Visaria, P and L .Visaria 1981: "Indian Population Scene after 1981 Census." Economic and Political Weekly, November (Special Issue): 1727-1780.

Waldron, I. 1983. "Sex Differences in Human Mortality: The Role of Genetic Factors." Social Science and Medicine, 17: 321-333. 